\title{
Mujer débil, pasiva y sumisa: la persona civil y los legados esencialistas en la Corte Penal Internacional
}

\author{
Weak, Passive, and Submissive Woman: The Civilian \\ and Its Essentialist Legacies at the International \\ Criminal Court \\ Mulher fraca, passiva e submissa: a pessoa civil e os \\ legados essenciais no Tribunal Penal Internacional
}

\section{Silvina Sánchez Mera*}

\author{
Fecha de recepción: 23 de abril de 2021 \\ Fecha de aprobación: 27 de julio de 2021
}

Doi: https://doi.org/10.12804/revistas.urosario.edu.co/anidip/a.11297

Para citar este artículo: Sánchez Mera, S. (2022). Mujer débil, pasiva
y sumisa: la persona civil y los legados esencialistas en la Corte Penal
Internacional. ANIDIP, 9, 1-26. Doi:https://doi.orğ/10.12804/revistas.
urosario.edu.co/anidip/a.11297

En nuestra lucha contra la impunidad, no dejemos a nadie atrás.

(Fatou Bensouda, 2019)

Cuando un barco se hunde, las reglas de rescate son claras: mujeres y niños primero.

(Hervé Diakiese, 2009)

\section{Resumen}

El estatus de civil es fundamental en el derecho penal internacional, puesto que son las víctimas por excelencia en los crímenes de lesa humanidad y en los de guerra. Sin embargo, el concepto se originó en el derecho de la guerra donde la idea del civil se construyó en torno a ciertas características que se le adscriben como esenciales. Este concepto y sus esencialismos han sido trasladados al campo del derecho penal 
internacional. Empleando una metodología feminista, este artículo busca mostrar esta construcción del civil como débil, pasivo, sumiso y femenino y cómo se manifiesta y naturaliza en la práctica de la Corte Penal Internacional (CPI). Se argumenta que esos esencialismos impiden una justicia de género a la vez que dan lugar a la impunidad al no representar correctamente las experiencias de las víctimas y silenciar ciertos crímenes.

Palabras clave: personal civil; Corte Penal Internacional; feminismo; víctima ideal; crímenes internacionales.

\begin{abstract}
For international criminal law, the status of the civilian is of outmost importance. Civilians encompass most of the protected groups against which war crimes and crimes against humanity are committed. Yet, the notion of the civilian belongs to the laws of war. It was in this realm where the idea of the civilian was constructed around certain characteristics, essentializing it. The concept of the civilian and its essentialisms has been transplanted to international criminal law. Using feminist methodologies, this essay seeks to show the construction of the civilian as weak, passive, submissive, and feminine; and how these characteristics are present and naturalized in the International Criminal Court's (ICC) practice. I argue that these essentialisms not only prevent gender justice but also pave the way to impunity, as they misrepresent victims' experiences and silence crimes.
\end{abstract}

Keywords: Civilian; International Criminal Court; feminism; ideal victim; international crimes.

\title{
Resumo
}

A condição civilé de fundamental importância no direito penal internacional, visto que por excelência são as vítimas dos crimes contra a humanidade e dos crimes de guerra. No entanto, o conceito teve origem no direito da guerra, onde a ideia de civil foi construída em torno de certas características que lhe são atribuídas como essenciais. Esse conceito e seus essencialismos foram transferidos para o campo do direito penal internacional. Utilizando uma metodologia feminista, este ensaio busca mostrar essa construção do civil como fraco, passivo, submisso e feminino, e como se manifestam e se naturalizam na prática do Tribunal Penal Internacional. Argumenta-se que esses essencialismos impedem a justiça de gênero ao mesmo tempo que dão origem à impunidade por não representar corretamente as experiências das vítimas e silenciar certos crimes.

Palavras-chave: pessoa civil; Tribunal Penal Internacional; feminismo; vítima ideal; crimes internacionais. 


\section{Introducción}

Las frases de Bensouda y Diakiese, presentadas como epígrafes de este artículo, contrastan notablemente. En la primera, la fiscal de la Corte Penal Internacional (CPI) recuerda el objeto y fin del establecimiento de la CPI y la persecución y castigo de los "crímenes más graves de trascendencia para la comunidad internacional" (Estatuto de Roma, Preámbulo, par. 2), a la vez que aspira al reconocimiento de las experiencias completas de los niños, las mujeres y los hombres víctimas de aquellas atrocidades. Mientras que la segunda, la declaración del representante de las víctimas en la CPI, pone en evidencia lo que la mente se imagina cuando piensa en "civiles" o en los "más vulnerables", que expresa exactamente lo que ocurre en la práctica de los tribunales internacionales en el tratamiento de las personas civiles.

Empleando una metodología feminista, este trabajo argumenta que los legados esencialistas, producto de una construcción de la noción del civil como débil, pasivo, sumiso y femenino, se hacen presentes en las prácticas de la CPI; misma que, al reproducir estos estereotipos, los refuerza y naturaliza. Se argumenta también que esto previene una justicia de género a la vez que da lugar a la impunidad al no representar correctamente las experiencias de las víctimas. Con ello no se pretende desacreditar el trabajo de los tribunales internacionales en general ni de la CPI en particular, ni los avances realizados hasta el momento en materia de género y de protección, sino iluminar los estereotipos y sus consecuencias con miras a generar cambios positivos.

El trabajo se divide en cuatro partes. La primera de ellas es esta introducción. La segunda parte está dedicada a la noción del civil y la construcción de los esencialismos que lo rodean. Consecuentemente se aborda la definición del civil prevista en el derecho internacional humanitario (DIH), el principio de distinción y las relaciones dicotómicas que este produce. Las dos secciones que la integran buscan demostrar la construcción esencialista del civil como débil, sumiso, pasivo y femenino, es decir, como un concepto generizado, ${ }^{1}$ y su reflejo en la práctica. La primera sección está dedicada a los esencialismos de debilidad, pasividad y sumisión, partiendo de la idea que la inmunidad de ataque del civil no es producto de una pasividad innata de aquel, sino la consecuencia reforzada por la construcción de ideales de indefensión. La segunda sección se presenta, en realidad, como un subesencialismo, esto es asociaciones y estereotipos dentro de la categoría del civil que refiere a la construcción del civil como femenino y las consecuencias que de ello derivan. 
La tercera parte se dedica al civil en el derecho penal internacional (DPI), que es el núcleo de este trabajo. Esta parte se divide en tres secciones. La primera desarrolla la importancia de la definición del civil en el DPI, resaltando que aquella es un producto del DIH que se traslada a este, junto con sus estereotipos y esencialismos. La segunda sección muestra cómo aquellos producen la "víctima ideal" y como esta opera reforzándolos en la práctica de los tribunales internacionales y las consecuencias que ello acarrea. La tercera sección se focaliza en la CPI por ser la única corte permanente que representa avances en materia de justicia de género. Sin embargo, se argumenta que los legados esencialistas tanto producto de la construcción del civil en DIH, como en la reproducción de la práctica en los tribunales internacionales se mantienen. Para ello se pasa a un estudio de caso, la sentencia más reciente de la CPI: caso Dominic Ongwen. La selección responde no solo a su novedad, sino a la importancia que tiene en materia de los delitos juzgados. A pesar de ello se sostiene que la práctica de la CPI está todavía lejos de lograr una justicia de género y sigue reproduciendo los legados esencialistas.

Por último, se concluye que los legados esencialistas previenen un abordaje integral de las experiencias de las víctimas, así como de los crímenes que contribuyen a la impunidad a la vez que refuerzan los estereotipos del civil. Para los fines de obtener una verdadera justicia de género y evitar la discriminación de género estos deben repensarse y deben reconstruirse las subjetividades en torno a la "víctima ideal".

\section{La noción de civil y sus esencialismos}

El artículo 50 del Protocolo Adicional I a los convenios de Ginebra de 1977 (PA I) define a la persona civil como "cualquiera que no pertenezca a una de las categorías de personas a que se refieren el artículo 4, A. 1), 2), 3), y 6), del III Convenio, y el artículo 43 del presente Protocolo" y establece que en caso de duda la persona debe ser considerada civil. Por su parte, el artículo 43 refiere a las fuerzas armadas de un Estado como combatientes, mientras que el artículo 4 de la III Convención de Ginebra indica quiénes deben ser considerados prisioneros de guerra. De esta manera, la definición de civil es negativa, es decir que todo aquel que no es combatiente es civil. La definición pertenece al ámbito del DIH. El principio de distinción, esto es distinguir "en todo momento entre población civil y combatientes, y entre bienes de carácter civil y objetivos militares" y dirigir las operaciones contra los objetivos militares (PA I, artículo 48) es una norma fundamental de naturaleza consuetudinaria (Henckaerts \& DoswaldBeck, 2005; Melzer, 2014). Lo que presupone este principio es que "la guerra debe 
conducirse contra las fuerzas armadas del enemigo, no contra su población civil" (Rogers, 1996, p. 7). ${ }^{2}$

A nivel práctico y en su faz personal, el principio de distinción implica diferenciar "en todo momento entre aquellas personas que pueden ser legalmente atacadas de aquellas que no, a quienes debe protegérseles de los efectos de las hostilidades" (Melzer, 2014, p. 297). ${ }^{3}$ Consecuentemente, ello provoca una división dicotómica entre el civil y el combatiente, ya que en un conflicto armado una persona es necesariamente categorizada como uno o lo otro. Además, esto genera ciertas presunciones o expectativas, en particular, con respecto a la conducta esperada por parte de los civiles.

Los estatus de civil y combatiente generan ciertos derechos y privilegios. A grandes rasgos, los combatientes están legalmente autorizados a participar activamente en las hostilidades (PA I, artículo 43.2), es decir, que su participación no puede ser perseguida legalmente, a la vez que se les reconocen ciertos privilegios: prisionero de guerra (Fleck \& Bothe, 2014). El estatus formal de combatiente y sus consecuencias jurídicas pertenecen únicamente al ámbito de los conflictos armados internacionales. En los conflictos armados de carácter no internacional, la figura no existe. $\mathrm{Ni}$ el artículo 3 común a los convenios de Ginebra ni el Protocolo Adicional II a los convenios de Ginebra (PA II), norma e instrumento respectivamente que abordan los conflictos armados no internacionales, mencionan al combatiente o proveen una definición de la persona civil. Aunque las personas en las fuerzas armadas del Estado son combatientes independientemente del tipo de conflicto armado (Henckaerts \& Doswald-Beck, 2005), no se predica lo mismo de los miembros de grupos armados, ya que estos no tienen derecho a participar en las hostilidades. Aquí la aplicación del principio de distinción no está dada, necesariamente, por una apreciación formal, sino que depende sustancialmente del comportamiento. La distinción, entonces, debe tener lugar entre quienes participan de las hostilidades y quienes no. ${ }^{4}$

Por su parte, los civiles no cuentan con el derecho a participar en las hostilidades, pero se benefician del principio de inmunidad, que implica que no pueden ser el objeto de ataque por parte del enemigo. Como se verá, esta concepción del civil ha sido construida en torno a esencialismos que condicionan las conductas de los beligerantes.

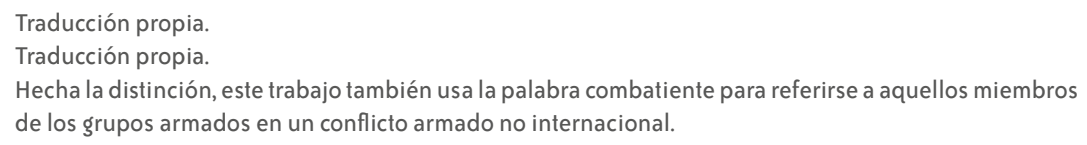




\subsection{El civil inocente es débil, sumiso y pasivo}

La justificación en otorgar inmunidad al civil se encuentra en la idea que los civiles, por ser débiles, sumisos y pasivos (o inocentes y vulnerables), ${ }^{5}$ no representan una amenaza en la conducción de las operaciones militares (Norman, 1995). No obstante, aquí se sostiene que la inmunidad del civil no es producto de una pasividad innata, sino, a la inversa, que su pasividad es consecuencia de la inmunidad, y su imagen como débiles y sumisos producto de una construcción subjetiva, que lleva a pensar al civil como "inocente".

La inmunidad que se le reconoce a la persona civil no depende de su estatus formal sino de su pasividad, ya que está condicionada por esta. Es el premio por ajustarse a un determinado comportamiento. Esto quiere decir que si el civil participa en las hostilidades pierde la inmunidad, así como cualquier privilegio otorgado a los combatientes (no tienen derecho a ser prisioneros de guerra), es decir, el castigo es mayor que en el caso de los combatientes. Segundo, el derecho a la inmunidad de ataque no es absoluto, ya que debe ponerse en la balanza junto a la necesidad militar. Esto significa que si bien el ataque no puede estar intencionalmente dirigido al civil, se permiten los "daños colaterales".

Hay quienes sostienen que la protección a los civiles existe desde tiempo inmemorial (Green, 2000; Jaworski, 2003), mientras que otros lo ven como un logro del Código de Lieber, los convenios de la Haya y las convenciones de Ginebra (DoswaldBeck, 1987). En realidad, la construcción de la subjetividad del civil y la exigencia de pasividad a los fines de reconocerles inmunidad al igual que la definición de civil son relativamente modernas. En cuanto a su definición, hasta la adopción del PA I no existía una enunciación de quién debía considerarse persona civil. Fue con el IV Convenio de Ginebra relativo a la protección debida a las personas civiles en tiempo de guerra en 1949 que la protección al civil se hizo explícita. Con anterioridad, la división solía ser entre combatientes y no combatientes —entendidos estos últimos como clérigos, médicos, mujeres, niños- (Alexander, 2007; Carpenter, 2006; Slim, 2016), categorías tradicionalmente consideradas sumisas y débiles. ${ }^{6}$

Así, por ejemplo, en los convenios de la Haya de 1899 y 1907, la distinción frente a lo que se permitía bombardear se condicionaba a la situación de indefensión o pasividad. Dichos convenios establecieron en sus respectivos artículos 25: "está prohibido atacar o bombardear, cualquiera que sea el medio que se emplee, ciudades, aldeas, habitaciones o edificios que no estén defendidos". Es importante destacar

5 Los adjetivos 'inocente' y 'vulnerable' se usan frecuentemente tanto en la narrativa de los trabajos preparatorios como en la de los tribunales.

6 Ejemplo de ello es el Tratado de Amistad y Comercio entre eE. uu. y Prusia de 1785 que establecía inmunidad para las mujeres, niños y campesinos (Roberts, 2019). 
que es a partir de estas normas que los conceptos de población civil y civil van a construirse subjetivamente. La idea de que se encuentra prohibido atacar ciudades cuando aquellas se encuentran indefensas contribuye a construir y fortalecer la idea de que la población civil, en general, y el civil, en particular, son (deben ser) indefensos y débiles. En realidad, lo que se hace es condicionar el ataque al comportamiento, no a su estatus.

Estas expectativas no se condicen necesariamente con la realidad. Originalmente ni la población civil ni la persona civil eran neutrales o pasivos en un conflicto. Los civiles tomaban partido y colaboraban activamente en el esfuerzo de la guerra en roles de apoyo (Slim, 2016) y "hasta la Primera Guerra Mundial los civiles eran percibidos como ciudadanos voluntariamente pasivos o deliberadamente peligrosos" (Alexander, 2007, p. 359). ${ }^{7}$ De acuerdo con Alexander (2007), el aspecto amenazante y peligroso de los civiles desapareció debido a la propaganda Aliada, que se encargó de presentar a los civiles, durante la ocupación de Bélgica, como víctimas indefensas.

A partir de allí, la narrativa del civil como inocente, es decir pasivo, sumiso y débil se hizo frecuente. Durante las negociaciones de los convenios de Ginebra de 1949, la mención del "civil inocente" fue usual (Conferencia Diplomática, 1949, pp. 404, 503, 645, 649, 718); además, se exaltaba su condición de víctima (Conferencia Diplomática, 1949, pp. 503, 718). Lo mismo ocurrió durante las negociaciones de los protocolos adicionales, en las que además se enfatizó la idea de indefensión, debilidad y pasividad (Conferencia Diplomática, 1974-1977, pp. 37, 97, 123, 178). ${ }^{8}$ A la vez, esa pasividad se presenta también como un deber, en palabras del brigadier Page: "ellos [los civiles] tienen un derecho a que se respete su vida y a la protección contra ataques ilegítimos y criminales; pero a cambio es su deber comportarse de una manera pacífica y no tomar parte en las hostilidades" (Conferencia Diplomática, 1949 , p. 621).

Las ideas de debilidad, pasividad y sumisión que rodean la noción de civil son una subjetividad construida que busca privilegiar las operaciones militares y beneficiar a los Estados en un conflicto, puesto que así no tienen que temer la reacción de la población civil o de las personas civiles, mientras que la obligación recíproca de no atacar civiles no es absoluta, esta depende de la necesidad militar. Se construyó así una idea del "civil inocente", donde la inocencia equivale a no participación en las hostilidades. No se trata de inocencia moral sino de una basada en agencia o en este caso, la falta de ella.

Traducción propia.

Las referencias provistas son ejemplificadoras y no exhaustivas de la cantidad de veces que se mencionan o hacen referencias a la pasividad, la inocencia y la debilidad del civil. 


\subsection{El civil como sinónimo de femenino}

La contribución del feminismo al derecho, en general, y al derecho internacional, en particular, resalta la naturaleza generizada de ciertos conceptos y enfatiza el uso de las dicotomías y los sesgos que las subyacen (Charlesworth, 2000). Así, de la división combatiente-civil se deriva una relación binaria que adscribe características masculinas al combatiente y femeninas al civil. El "civil inocente" - débil, pasivo y sumiso - es un concepto generizado. Los atributos de debilidad, sumisión y pasividad son características tradicionalmente relacionadas a lo "femenino" (Carpenter, 2006; Cohn, 1993; Kinsella, 2006, 2011), por lo que la noción de civil no está solo vinculada a las ideas de pasividad, sumisión y debilidad, sino también a un prejuicio de género.

De lo anterior deriva que la idea del civil generalmente se asocia con mujeres, niños y ancianos, pero no con hombres adultos (Carpenter, 2006, p. 2). Al contrario, la idea del combatiente está generalmente asociada con hombres adultos. Consecuentemente, a pesar de que las normas del DIH no distinguen entre civiles y combatientes a partir del género (o el sexo), la idea del civil ha sido permeada por ideas basadas en género, por ello es un concepto generizado.

Aun cuando "todos los civiles tienen que ser protegidos con base en sus acciones y roles sociales, en la práctica solo ciertas categorías de la población (mujeres, niños, ancianos, enfermos) se presumen civiles independientemente del contexto" (Carpenter, 2006, p. 13)..$^{9}$ Esto implica que las mujeres y los niños son objetos de protección como civiles por defecto. Si bien es correcto afirmar que en los conflictos armados hoy la mayoría de las mujeres son civiles, también lo es decirlo sobre los hombres (Lindsey, 2001). Sin embargo, la presunción automática de las mujeres como civiles las identifica como débiles, pasivas y sumisas a la vez que refuerza la idea de que la guerra es una cuestión de hombres, donde los agentes son los hombres y las víctimas, las mujeres. No se busca aquí sostener que los hombres no son nunca considerados como civiles y, a la inversa, que las mujeres siempre son consideradas civiles, sino que la presunción de civil opera más fácilmente en relación con las mujeres, mientras que la de los hombres se cuestiona o se puede cuestionar.

En 2002 cuando Estados Unidos (EE. UU.) bombardeó una fiesta de casamiento en Afganistán, uno de los justificativos fue la "imposibilidad de distinguir hombres de mujeres y niños de adultos" (U. s. Central Command, 2002), ${ }^{10}$ no combatientes de civiles, porque aquí los hombres adultos son considerados automáticamente combatientes. En este ejemplo existe una presunción ipso facto de que las mujeres y

\footnotetext{
$9 \quad$ Traducción propia.
}

10 Traducción propia. 
los niños son civiles mientras que se presume que los hombres son combatientes y por ello blancos legítimos de combate. Kinsella (2006) asevera que "invocar a las mujeres, niños y ancianos también identifica y racionaliza la diferencia entre el combatiente y el civil, que luego determina la diferencia entre actos permitidos y no permitidos en la guerra" (p. 163). ${ }^{11}$

Estos preconceptos se remontan a la época de Grocio (año 1625), quien de alguna manera veía a mujeres y niños como categorías merecedoras de protección durante la guerra. El Código de Lieber mensiona expresamente a las mujeres y los niños como no combatientes; establece que "los comandantes, en lo posible, informarán al enemigo de su intención de bombardear un lugar para que los no combatientes, específicamente las mujeres y los niños, sean evacuados" (artículo 19) ${ }^{12} \mathrm{u}$ objetos de protección (artículo 37). En similar sentido, el IV Convenio de Ginebra de 1949, dedicado a la protección de los civiles, no protege a todos los civiles de igual manera. ${ }^{13} \mathrm{El}$ convenio hace referencia a cierta categoría de civiles a quienes se les debe una protección especial. ${ }^{14}$ En particular: enfermos; mujeres gestantes, lactantes o con hijos pequeños, y niños (artículos 14, 24, 38, 50). Esta protección está también basada en un prejuicio, las mujeres se protegen porque son esenciales para el cuidado de los niños. La idea que subyace, por lo tanto, es que las mujeres son intrínsecamente las cuidadoras y encargadas de la crianza de los niños, reforzando así su rol de madres (PA I, 1977a, artículos 75.2, 76). Esto no solo fortifica el estereotipo de género sobre las mujeres, sino sobre el civil que se convierte en femenino y débil. Las resoluciones en el marco de la Agenda del Consejo de Seguridad de las Naciones Unidad sobre mujeres, paz y seguridad también han sido criticadas por promover la figura de la mujer como objeto de protección (Shepherd, 2008) que "refuerzan el vínculo entre feminidad y victimización” (Hodgson, 2017, p. 340). ${ }^{15}$

La universalización y esencialidad de las características asociadas con la feminidad y la niñez, y la invisibilización de quienes no se conforman con ese esencialismo no solo descartan la posibilidad que las mujeres sean combatientes, ${ }^{16}$ sino que además promueve una imagen del hombre como aquel que no es inocente (pasivo o sumiso) ni vulnerable —débil- (Enloe, 1998; Lindsey, 2001). En su esfera práctica, este esencialismo de género puede tener consecuencias fatales para los hombres. Algunas

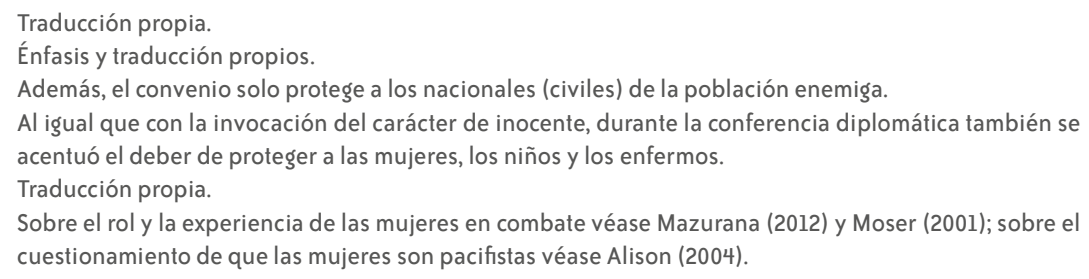


investigaciones sugieren que los hombres civiles son más propensos que las mujeres civiles a ser ejecutados en un conflicto armado (Jones, 2000). En esta línea, Carpenter (2006) ha demostrado cómo, durante el conflicto de la ex Yugoslavia, las masacres selectivas a los miembros masculinos de la sociedad reflejan la construcción del combatiente contra el civil. Los hombres en edad de combate fueron asesinados porque eran vistos como potenciales combatientes, no así las mujeres.

En cuanto a las consecuencias para las mujeres, la primera es la perpetuación de la negación de agencia de la mujer, "así como las potenciales narrativas perjudiciales en torno a la protección y la vulnerabilidad sexual" (Heathcote et al., 2021, p. 162). ${ }^{17}$ Ello implica construir a la mujer como objeto de protección y no como sujeto de protección o cambio. O bien, por ejemplo, focalizar la violencia sexual contra las mujeres "como la expresión paradigmática de la construcción de la mujer como símbolo de honor o propiedad del hombre" (Kinsella, 2006, p. 165), ${ }^{18} \mathrm{el}$ refuerzo de "estereotipos de feminidad que se corresponden con visones europeas" (Gardam, 1997, p. 249), ${ }^{19} \mathrm{y}$ dar por sentado cualidades "naturales" como la maternidad y la necesidad de proteger a la mujer en función de su habilidad reproductiva (Gardam, 1997; Heathcote, 2016). Además, su invisibilización como combatientes previene esfuerzos de desmovilización (Annan et al., 2011).

\section{Mujer débil, sumisa y pasiva: la persona civil en el derecho penal internacional}

\subsection{Importancia del civil en el derecho penal internacional}

En el Estatuto de Roma de la CPI, el civil como categoría de protección pertenece tanto al ámbito de los crímenes de guerra como a los de lesa humanidad. Los crímenes de guerra abarcan una larga lista de delitos y las víctimas, dependiendo del acto en cuestión, pueden ser tanto civiles como combatientes. Hay delitos donde el estatus de la víctima es lo central, tal es el caso del uso de una persona civil como escudo humano (Estatuto de Roma, artículo 8.2.b.xxiii) o matar a traición al combatiente enemigo (Estatuto de Roma, artículos 8.2.b.xi, 8.2.e.ix). Aun así, en la mayoría de los delitos, las víctimas no se diferencian tanto por su estatus como por su comportamiento. En algunos casos, tal como el crimen de dirigir ataques a la población civil o contra personas civiles, tanto el estatus de la persona como su comportamiento son relevantes a los fines de determinar su situación

\footnotetext{
17 Traducción propia.

18 Traducción propia.

19 Traducción propia.
} 
de víctima (Estatuto de Roma, artículo 8.2.b.i). Por lo que debe haber una doble evaluación: determinar si la víctima es civil, en cuyo caso se determinará si al momento del hecho participaba o no activamente de las hostilidades. En otros casos el estatus de la víctima es irrelevante y lo que importa es su conducta al momento del hecho. Tal es el caso del homicidio (Estatuto de Roma, art. 8.2.c.i): para constituir delito aquel debe cometerse en contra de una persona que no participe activamente de las hostilidades o esté fuera de combate.

Donde el estatus de civil deviene fundamental es en el crimen de lesa humanidad, ya que uno de los elementos contextuales de tipo penal es la necesidad que el ataque en cuestión esté dirigido contra la población civil (Estatuto de Roma, art 7.1). ${ }^{20}$ El motivo responde a los orígenes de este crimen y su estrecha vinculación con la guerra, ya que "en su formación el concepto de crímenes de lesa humanidad era esencialmente una extensión del derecho de la guerra" (de Guzman, 2011, p. 62). ${ }^{21}$ La noción de crímenes de lesa humanidad emergió como una respuesta a crímenes colectivos a manos de un Estado contra su propia población (de Guzman, 2012; Rodenhäuser, 2018), en particular, a las atrocidades nazis contra su propia población. Puesto que dichos crímenes caían fuera de la esfera de los crímenes de guerra que solo protegían a los nacionales de la potencia enemiga, no así a los propios (Robinson, 1999), cuya codificación se dio en el Estatuto Militar de Nuremberg:

Crímenes Contra la Humanidad: A saber, el asesinato, la exterminación, esclavización, deportación y otros actos inhumanos cometidos contra población civil antes de la guerra o durante la misma; la persecución por motivos políticos, raciales o religiosos en ejecución de aquellos crímenes que sean competencia del Tribunal o en relación con los mismos (artículo 6. c). ${ }^{22}$

Schabas (2007) recuerda que los Aliados temieron por las repercusiones que el crimen de lesa humanidad pudiera tener sobre el trato a las colonias, por lo que decidieron "atar" el crimen de lesa humanidad a los otros crímenes del Estatuto. Bassiouni (2011) entiende que el motivo fue porque la conexión con la guerra era la única forma de extender la protección a la población civil de los Estados (p. 33).

Nuremberg se convirtió en una "fuente de inspiración" para los tribunales internacionales (Bryant, 2015, p. 211). ${ }^{23}$ Con los años el crimen de lesa humanidad presentó algunas variaciones como el mantenimiento de un nexo con el conflicto

\footnotetext{
Cursivas fuera del orioginal.

Traducción propia.

Cursivas fuera del orioginal.

Traducción propia.
} 
armado en el artículo 5 del Estatuto del Tribunal Internacional Penal de Yugoslavia (TIPY) o la inclusión de un elemento discriminador en el artículo 3 del Estatuto del Tribunal Internacional para Ruanda (TIPR) y en el artículo 5 del Estatuto de las Salas Extraordinarias de las Cortes de Camboya. Lo que se mantuvo constante fue el requisito "civil" de la población atacada. Tal es así que todos los estatutos de los tribunales internacionales que tienen jurisdicción sobre este crimen lo mantienen. El Estatuto de la CPI, al igual que el Estatuto del Tribunal Especial para Sierra Leona (artículo 2), no requiere la existencia de un conflicto armado ni contiene el elemento discriminador. El artículo 7. 1. del Estatuto de Roma establece: “a los efectos del presente Estatuto, se entenderá por 'crimen de lesa humanidad' cualquiera de los actos siguientes cuando se cometa como parte de un ataque generalizado o sistemático contra una población civil y con conocimiento de dicho ataque".

A pesar de que el "civil" es prácticamente central en la persecución de estos crímenes, ningún estatuto ha provisto una definición de qué o quién debe entenderse por civil. En la sentencia de Nuremberg, recordando que a esa fecha tampoco existía en el DIH una definición de civil, el tribunal optó por un abordaje de sentido común sin explicitarlo, todo aquel que no pertenecía a las fuerzas armadas de los Estados beligerantes era civil (Sentencia Nuremberg, p. 41). Los restantes tribunales, incluida la CPI, han tomado la definición directamente del artículo 50 del PA I (Prosecutor c. Kayishema y Ruzindana, 1999; Prosecutor c Blaškić, 2004; Prosecutor c. Sessay et al., 2009; Case 001, 2010; Prosecutor c. Ongwen, 2021), indicando además que la misma tiene carácter consuetudinario (Prosecutor c. Blaškić, 2004).

$\mathrm{Al}$ ser los crímenes de guerra violaciones graves al DIH (Cassese, 2011; Dörmann, 2003; Triffterer \& Ambos, 2016) es acertado trasladar las definiciones de combatiente y civil al ámbito del DPI. No obstante, en el caso de los crímenes de lesa humanidad hacer lo mismo no resulta del todo lógico. Primero, porque no existe hoy necesidad de un nexo con el conflicto armado. Segundo, porque los crímenes de lesa humanidad pueden ser cometidos tanto en tiempos de paz como de guerra. En ausencia de un conflicto armado toda la población podría considerarse civil. Es más, cuando los Estados comenten estos crímenes no necesariamente hacen uso de sus fuerzas armadas para llevarlos a cabo, la policía y funcionarios civiles pueden ser los perpetradores directos, como ocurrió en Camboya durante el régimen del Khmer Rouge. La conexión histórica entre el crimen de lesa humanidad y la guerra (Bassiouni, 2011) es la que produce la remisión a las nociones del DIH, independientemente de si concuerdan con el contexto. La mayor consecuencia de trasladar una definición del civil del DIH a los crímenes de lesa humanidad radica en que con ella se traslada también la construcción de subjetividad del civil y sus imaginarios o sesgos. 


\section{2. Los esencialismos del civil y la "víctima ideal" en la jurisprudencia internacional}

Las secciones precedentes apuntan a mostrar los esencialismos del civil y su construcción como débil, pasivo, sumiso y, por sobre todo, su feminización como aquel concepto central en el DPI que se aplica por referencia al DIH independientemente de la existencia de un conflicto armado. El civil es entonces, en el DPI, también una noción generizada. Esto se observa en la narrativa de las sentencias internacionales y el tratamiento de los crímenes internacionales, lo que a la vez robustece los estereotipos de debilidad, pasividad, sumisión y feminidad.

Esta construcción promueve y refuerza la noción de "víctima ideal”. Siguiendo a Christie (1986), la "víctima ideal" es "una persona o categoría de individuos que, al ser afectada por un crimen, se les otorga, sin cuestionar, un completo y legítimo estatus de víctima" (p. 18). ${ }^{24}$ La "víctima ideal" de este autor posee determinados atributos: es débil, vulnerable, realiza una actividad respetable (al momento de los hechos), no se la puede responsabilizar por encontrarse en el lugar de los hechos y el ofensor es más grande y perverso que ella (p. 19). En otras palabras, una víctima que se ajusta a los estereotipos de feminidad e inocencia (debilidad, sumisión y pasividad) es una "víctima ideal". Sin embargo, aquí se sostiene que la "víctima ideal" no es un concepto linear, sino que pueden encontrarse distintos "ideales" en función de los actos criminales en cuestión, que generan, si se quiere, subcategorías o capas. Simplificando, hay víctimas que son "ideales" para ciertos crímenes. Esto quiere decir que aun cuando el "civil inocente" es la "víctima ideal" de los crímenes de lesa humanidad, las mujeres, por ejemplo, son las "víctimas ideales" de los delitos sexuales dentro de esta categoría.

La consecuencia de ser una "víctima ideal" es, como se dijo anteriormente, la aceptación del estatus sin cuestionar. Esto repercute en las investigaciones y en las sentencias internacionales, ya que la tendencia inconsciente es localizar y construir a estas "víctimas ideales". La situación se vuelve entonces un círculo vicioso; los esencialismos del civil provocan una construcción subjetiva de la "víctima ideal". A su vez, cuando aquella se manifiesta (o se presenta) en los procesos judiciales, su imagen tiende a reforzar la naturalización de esos estereotipos de género que la originaron en primer lugar. Adicionalmente, contribuye también a oscurecer o impedir las "zonas grises", 25 abriendo el camino a situaciones de impunidad y de desconocimiento de experiencias de victimización.

\footnotetext{
24 Traducción propia.

25 En relación con las zonas ǵrises véase Brown, (2013) y Levi (1989).
} 
La generización del civil y la búsqueda de la "víctima ideal" explican varias situaciones que tienen lugar en las sentencias de los tribunales. Por ejemplo, la idea que son siempre los combatientes los perpetradores y los civiles las víctimas, respaldada por una narrativa que refuerza la idea de "inocencia" — debilidad, pasividad y sumisión - de los civiles para legitimar su victimización. Así, el "ataque a civiles inocentes" o "la muerte de civiles inocentes" son frases frecuentes en las sentencias. (Prosecutor c. Erdemović, 1997, par. 19; Prosecutor c. Stakić, 2003, par. 58; Nahimana et. al, 2003, par. 1038; Rutaganira, 2005, par. 161). Las Cortes Especiales de Sierra Leona explicitan el nexo entre la inocencia y la abstención de participar activamente en las hostilidades (Prosecutor c. Sessay et.al, 2009, par. 954). La narrativa ayuda a reforzar así la noción del civil como "víctima ideal" y, dentro de los civiles, que es peor atacar a mujeres y niños (Blaškić, 2004; Rutaganira, 2005).

Esta construcción explicaría también la poca cantidad de acusadas mujeres en los tribunales internacionales, un $1.1 \%$ de los acusados (Hodgson, 2017, p. 341), no porque las mujeres no cometan crímenes, sino simplemente porque el esencialismo de género que se impone es el de la inocencia. Se recuerda que a las mujeres se las tiende a considerar civiles por defecto (Carpenter, 2006). Ello tiende a minimizar su participación en crímenes internacionales o a que no se contemple siquiera la posibilidad y mucho menos, su investigación. ${ }^{26}$

En las investigaciones penales esto puede llevar, además, a invisibilizar a los varones como víctimas de violencia, en particular como víctimas de violencia sexual, a la vez que se hipervisibiliza la de la mujer de una manera que promueve la supremacía masculina (Chinkin \& Kaldor, 2013). Zarkov (2001), al referirse al conflicto en la exYugoslavia sostiene: "la violación sexual de las mujeres generó interés mediático, la de los hombres no" (p. 72). ${ }^{27}$ En esta línea, el trato de la violación sexual a hombres por parte de los tribunales varía desde su omisión (Prosecutor c. Bagosora et al., 2008; Prosecutor c. Sessay et al., 2009; Prosecutor c. Taylor, 2012 ${ }^{28}$ hasta tratarlo como tortura (Prosecutor c. Mucić et al., 1998; Prosecutor c. Simić et al., 2003). ${ }^{29}$ Caracterizar la violación sexual de los hombres solo como tortura es problemático porque promueve una imagen de que los hombres no son pasibles de violencia sexual y que esta es un problema de las mujeres (Sivakumaran, 2010). Con relación a cómo se fomentan y refuerzan ideas generizadas de la violencia sexual, el

26 Los obstáculos en el acceso de las mujeres a cargosos de jerarquía también pueden explicar la falta de perpetradoras mujeres, al menos en ciertos tribunales internacionales que tratan con "perpetradores jerárquicos".

27 Traducción propia.

28 En Bagosora, se reconoce la existencia de la violación, pero solo sirve para contextualizar el caso.

29 Existen casos de imputación de violación contra hombres que han llevado a convicciones en alğunos casos, por ejemplo, Češić (2004), Bemba (2016) absuelto en apelación. 
tratamiento que ciertos tribunales llevan a cabo sobre la violencia sexual a la mujer tiende a reforzar estas ideas. ${ }^{30}$

Asociar automáticamente a las mujeres (y niñas) con violencia sexual no solo puede resultar en su marginalización como víctimas de otros crímenes "convencionales" o dominantes (Grewal, 2015, p. 150), sino que también opera como una forma de acentuar las diferencias de género en base a la vulnerabilidad (debilidad) sexual (Kinsella, 2006). Estas prácticas están internalizadas en el seno de los tribunales y se reflejan en las sentencias judiciales. Operan como refuerzo de conceptos estereotípicos cuya consecuencia es prevenir un abordaje de justicia integral y el reconocimiento de las experiencias reales de las víctimas de delitos internacionales. La generización del civil hace que se privilegien ciertos grupos por sobre otros.

\subsection{Débil, pasiva y sumisa: los esencialismos de la CPI en el caso \\ Dominic Onğwen}

La adopción del Estatuto de Roma representó un avance en materia de justica de género. Años de presión de grupos feministas se vieron reflejados en disposiciones que demandaban una representación equilibrada de magistrados (artículo 36.8.a.iii) y jueces especializados en violencia contra las mujeres y los niños (artículo 36.8.b), así como en la lista de crímenes sexuales y de género y el establecimiento de la Unidad de Género y Niños en la Fiscalía. A su vez, la Fiscalía (2014) en su Documento de política sobre crímenes sexuales y por motivos de género se comprometió a "incorporar la perspectiva y el análisis de género" (par. 5) y a evitar "cualquier discriminación de género" en toda su labor.

No obstante, la construcción del civil como débil, pasivo, sumiso y femenino se hizo presente y se incrustó en el espíritu del estatuto, así como en la práctica posterior del tribunal. Durante las negociaciones, los esencialismos con relación al civil fueron acentuados; los delegados exaltaron de manera frecuente la necesidad de protección de las mujeres y los niños frente a la violencia, así como su calidad de civiles y su situación de vulnerabilidad — debilidad- (Conferencia Diplomática, 1998). El estatuto también hizo lo propio, por ejemplo, al referir a la esclavitud menciona: "Por 'esclavitud' se entenderá el ejercicio de los atributos del derecho de propiedad sobre una persona, o de algunos de ellos, incluido el ejercicio de

30 Por ejemplo, en Sierra Leona, el primer tribunal en juzģar el delito de matrimonio forzado, la Jueza Doherty (Prosecutor c. Brima et al., 2007) encontró que: “La intención del esposo fue obliģar a la víctima a cuidarlo y satisfacer sus necesidades sexuales, a serle leal y fiel y a tener sus hijos. A cambio, él la protegería contra abusos sexuales por parte de otros hombres y la alimentaría. En efecto estos son derechos y obligaciones de quienes, tal como lo indicó la defensa, se involucran en un matrimonio tradicional, pero aquí no existe el asentimiento de la familia de la mujer y el estatus de esposa es forzado" (par. 49) (traducción propia). 
esos atributos en el tráfico de personas, en particular mujeres y niños" (Estatuto de Roma, artículo 7.2.c), ${ }^{31}$ lo que termina siendo una espada de doble filo. Por un lado, implica el reconocimiento de crímenes cometidos contra estos grupos, por el otro opera como refuerzo de los estereotipos de debilidad y las nociones de que solo las mujeres pueden ser víctimas de violencia sexual y de género.

A ello se suma la práctica de la Fiscalía en la construcción de la "víctima ideal", que es retomada por las cámaras. Así, al día de hoy, la CPI ha replicado los legados esencialistas construidos en torno a la subjetividad del civil y de lo que este debe ser o cómo debe comportarse en su jurisprudencia. Como se verá a continuación, evitar la discriminación de género e incorporar dicha perspectiva sigue siendo una aspiración.

La construcción de la "víctima ideal" como mujer débil, pasiva y sumisa se ve reflejada en su última sentencia. El pasado 4 de febrero, la CPI sentenció a Dominic Ongwen, excomandante del Ejército de Resistencia del Señor (ERS) por una lista sustancial de crímenes internacionales. Ongwen es importante por distintas razones: es la primera condena en la situación de Uganda, investigación que empezó hace 17 años; es la persona condenada a la mayor cantidad de crímenes hasta el momento en la CPI, 61 cargos que incluyen tanto crímenes de guerra, como de lesa humanidad, entre ellos se le atribuyen crímenes de los cuales él fue una vez víctima, reavivando así el debate sobre las víctimas-perpetradores; representa para la CPI la primera condena por matrimonio forzado, y la primera a nivel internacional por embarazo forzado. Además, hubo un reconocimiento explícito a las víctimas, cuyos nombres fueron leídos por el juez a la hora del veredicto, algo insólito hasta el momento, pero sin duda causa de celebración.

Sin embargo, no todo lo que brilla es oro. Ongwen es también un ejemplo de cómo operan los esencialismos del civil y cómo se refuerzan esos estereotipos. Se busca mostrar, de forma sintética, cómo lo hasta aquí desarrollado se manifiesta en las investigaciones y consecuentemente en las sentencias de la CPI. A tal fin, el foco está puesto en dos aspectos de la sentencia: los cargos por esclavitud (crimen de lesa humanidad) y tortura (crimen de lesa humanidad y de guerra), y los abusos sexuales cometidos contra mujeres y niñas (crimen de lesa humanidad y de guerra).

Una de las prácticas habituales del ERs fue el secuestro de personas civiles tanto adultas como menores de edad para acrecentar las filas de soldados (Prosecutor c. Ongwen, 2021, par. 895, 1973). Estimaciones indican que del total de las filas del ERS, un $25 \%$ corresponde a mujeres secuestradas y un $47 \%$ a hombres secuestrados

31 Cursivas fuera del oriģinal. 
—edades 14-35- (Annan et al., 2011). Además, "la violencia y las amenazas de castigo eran los principales medios de control [sobre los reclutas secuestrados] del ERs" (Blattman \& Annan, 2010, p. 140), situación acreditada en Ongwen. En palabras simples, esto implica que una gran cantidad de personas fueron obligadas a combatir.

El fiscal imputó y el Tribunal de Juicio encontró a Ongwen culpable por esclavitud y tortura (par. 1068) en relación con el secuestro de personas civiles tanto hombres como mujeres de diferentes edades, pero solo con respecto al transporte de mercadería y heridos al campamento, por entender que habían sido puestos bajo vigilancia y amenazados de muerte para prevenir que escapasen además de los maltratos y golpes para que caminaran más rápido (par. 2839). No hay reflejo de lo que acontece después de la llegada al campamento en los cargos penales, excepto en el caso de los menores de 15 años (niños soldado) y las mujeres. En estos casos, el fiscal imputó por esclavitud y tortura con relación a las mujeres una vez que aquellas llegaban al campamento y eran incorporadas al ERs y por reclutamiento de niños soldado; cargos que también fueron corroborados en la sentencia.

Lo que muestra la sentencia, entonces, es cómo operan los esencialismos del civil. La idea de la "víctima ideal", el civil como mujer débil, pasiva y sumisa. Aun cuando el ambiente coercitivo es idéntico (incluso con referencias a asesinatos de personas que han intentado escapar) - fue demostrado que este es el modus operandi del ERs y se acreditó que los civiles eran forzados a combatir-, en el momento en que el hombre civil adulto es obligado a tomar las armas deja de ser merecedor del estatus de víctima.

En relación con las mujeres y niñas, parte de su experiencia es invisibilizada y solo se las considera como objeto de abusos sexuales. A pesar de que la prueba indica que en cualquier momento dado (del periodo comprendido en los cargos: 1 de julio de 2002 al 31 de diciembre de 2005) habría más de 100 mujeres secuestradas en la Brigada Sinia (par. 213), ${ }^{32}$ que testigos hablaron de cómo identificaban la existencia del ataque por el aullido de las mujeres (par. 1249) y del entrenamiento militar que seguía a los secuestros (par. 423), y que la propia CPI reconoció estos hechos, es el propio tribunal el que minimiza su participación al sostener: "No obstante existir evidencia de la participación de miembros femeninos del ERs en entrenamiento y combate, la prueba que se discute a continuación indica que el rol del combatiente era principalmente para los hombres" (par. 894). ${ }^{33} \mathrm{Al}$ invisibilizar o descartar su rol de combatiente, las mujeres fueron consideradas victimas ipso

\footnotetext{
32 El ERS se conformaba de 4 grandes brigadas, la Sinia era la comandada por Onģwen y es por ello que la referencia es solo en relación a ella (Prosecutor c. Onǵwen, 2021, par.123). 
facto, lo que además permitió imputar por esclavitud y tortura durante la estadía en el ERs. En cambio, la narrativa de la Fiscalía (y del tribunal) se focalizó en el rol de las mujeres y niñas en el ERs, que en la sentencia se reduce a su consideración como objetos de abuso sexual.

La sentencia, entonces, analiza con profundidad las políticas del ERS en cuanto al secuestro de mujeres y niñas, principalmente a los aspectos de matrimonio y embarazo forzado y esclavitud y violación sexual (pars. 214-220, 2098, 2814). Estos delitos tienen por víctimas exclusivamente a las mujeres, no hay un solo cargo por abuso sexual a hombres, pese a la existencia de abusos a niños (ONUCDH, 2000). Así, la CPI encontró "que la brigada Sinia llevó a cabo un esfuerzo metódico para secuestrar a mujeres y niñas en el norte de Uganda y forzarlas a servir en la Brigada como 'esposas' y como servicio doméstico" (par. 212). ${ }^{34} \mathrm{Si}$ bien las mujeres (y niñas) han sido desproporcionadamente afectadas, puesto que además de combatir han sido sometidas a abusos sexuales en mayor medida que los hombres (y niños), reforzar el papel de la mujer como "esposa" implica oscurecer la realidad de las experiencias de esas mujeres, ya que hay una parte de la historia que se está omitiendo: no hay reconocimiento general de las mujeres combatientes o de las niñas soldado. La sentencia no contempla un cruce entre las mujeres que pelean y aquellas abusadas sexualmente, invisibilizando una porción de su experiencia real.

Tampoco se habla de los abusos sexuales de aquellas mujeres que integran el ERS voluntariamente, es decir, que no hayan sido secuestradas (Annan et al., 2011). Téngase presente que la CPI ha determinado que la violación está siempre prohibida, independientemente del estatus de la víctima (Fiscal c. Ntaganda). En este caso la agencia de la mujer (integración voluntaria al ERs) se castiga. Esta falta de reconocimiento solo sirve para acrecentar los estereotipos que las mujeres son débiles, pasivas y sumisas, en últimas, que carecen de agencia; al tiempo que "reducen la experiencia e identidades de las mujeres y niñas al marco de la violencia sexual" (Grewal, 2015, p. 153). ${ }^{35}$ Adicionalmente, al construir la "víctima ideal" se refuerzan las estructuras patriarcales, ya que las mujeres solo son presentadas como las esposas o amas de casa o por su función reproductiva.

Con las niñas soldado, la cuestión se vuelve un tanto confusa. En primer lugar, cabe decir que el conflicto en Uganda es famoso por el reclutamiento de niños y niñas soldado a manos del ERS, estudios indican que un $40 \%$ de los niños soldado son, en realidad, niñas (Drumbl, 2012; Singer, 2015). Además, reportes muestran que "a las niñas se les daban armas y entrenamiento militar" (Gustavsson et al.,

\footnotetext{
$34 \quad$ Traducción propia.
}

35 Traducción propia. 
2017), ${ }^{36}$ por lo que es impensable que en las filas del ERs no haya habido niñas soldado. Dicho esto, la CPI al referir a los niños soldado ha hecho referencias a "child" o "children" (par. 3102), que como con su equivalente en español abarcaría, en principio, ambos géneros. Sin embargo, en sentencias anteriores, la CPI ha marcado la diferencia al hablar de niños y niñas soldado (Prosecutor c. Lubanga, 2012; Prosecutor c. Ntaganda, 2019). A ello se suma la insistencia de la CPI que los "hombres son soldados y las mujeres esposas". Esto lleva a cuestionar si es una invisibilización del papel de las niñas en los conflictos armados y si, al igual que con sus pares adultas, solo se presentan como víctimas de violencia sexual.

Como se observa, Ongwen es un claro ejemplo de la continuación de los legados esencialistas en torno al civil, de cómo la masculinidad sigue reflejada en la violencia y dominación, mientras que la feminidad se refleja en la victimización (Hodgson, 2017, p. 340). Muestra también la decisión de contar una parte de la historia para mantener la imagen de "victima ideal", una víctima que es mujer, débil, pasiva y sumisa.

\section{Conclusión}

El presente trabajo ha intentado mostrar cómo la construcción de ideales sobre el civil, originados en el DIH, influye y afecta las sentencias de la CPI, quien no permanece ajena a la reproducción de estos estereotipos. Estos legados esencialistas se encuentran incrustados en la práctica de los tribunales internacionales. Por consiguiente, el traslado del concepto de civil, y con ello de los estereotipos que lo integran, no solo promueve el mantenimiento de estructuras patriarcales, sino que imposibilita valorar íntegramente a las víctimas.

Los ideales subjetivos que rodean a la persona del civil construyen una imagen de aquel como débil, pasivo, sumiso y femenino, que impacta negativamente en las investigaciones judiciales internacionales y en sus resultados. El discurso esencialista y las ideas que este impone marginalizan a quien no se conforma con las expectativas al punto de invisibilizarlo en las investigaciones internacionales, lo que impide a la CPI lograr una justicia de género. Tal como lo demuestra la última sentencia de este tribunal (Ongwen), donde las narrativas de inclusión y exclusión; la decisión de imputar ciertos crímenes, y el reconocimiento y la valoración de la agencia de las víctimas (o la falta de ella) terminan sosteniendo los estereotipos de género y sus esencialismos tanto sobre hombres como mujeres. Esto deviene en un no-reconocimiento de las experiencias completas de las víctimas, el silencio tanto de las vivencias, como de los crímenes, lo que, a su vez, allana el camino a la impunidad. 
A pesar de su compromiso con una justicia de género y evitar la discriminación por género, queda trabajo por hacer para lograr este objetivo. Debe haber esfuerzos reales para reconstruir la imagen de la víctima ideal, para reestructurar y repensar subjetividades y prácticas con miras a una completa protección de las víctimas, de sus historias y del abordaje de los crimines internacionales. Para que en "nuestra lucha contra la impunidad, no dejemos a nadie atrás" (Bensouda, 2019). ${ }^{37}$

\section{Referencias}

Alexander, A. (2007). The genesis of the civilian. Leiden Journal of International Law, 20(2), 359-376. https://doi.org/10.1017/S0922156506003347

Alison, M. (2004). Women as agents of political violence: Gendering security. Security Dialogue, 35(4), 447-463. https://doi.org/10.1177/0967010604049522

Annan, J., Blattman, C., Mazurana, D., \& Carlson, K. (2011). Civil war, reintegration, and gender in northern Uganda. The Journal of Conflict Resolution, 55(6), 877-908.

Bassiouni, M. C. (2011). Crimes against humanity: Historical evolution and contemporary application. Cambridge University Press.

Bensouda, F. (25 noviembre, 2019). Statement of ICC Prosecutor, Fatou Bensouda. https://www.icc-cpi.int/Pages/item.aspx?name=191125-otp-statement-International-Day-Elimination-Violence-against-Women

Blattman, C., \& Annan, J. (2010). On the nature and causes of LRA abduction: What the abductees say. In T. Allen \& K. Vlassenroot (Eds.), The lord's resistance army: Myth and reality (pp. 132-155). Zed Books. http://ebookcentral. proquest.com/lib/latrobe/detail.action?docID $=579116$

Brown, A. (2013). Judging 'privileged' jews: Holocaust ethics, representation, and the 'grey zone,' vol. 18. Berghahn Books.

Bryant, M. S. (2015). A world history of war crimes: From antiquity to the present. Bloomsbury Publishing Plc.

Carpenter, R. C. (2006). 'Innocent women and children': Gender, norms and the protection of civilians. Taylor \& Francis Group.

Cassese, A. (Ed.). (2011). International criminal law: Cases and commentary. Oxford University Press.

37 Traducción propia. 
Central Command, United States of America. Unclassified Executive Summary: Investigation of Civilian Casualties, Oruzgan Province, Operation Full Throttle 30 June, 2002. (6 septiembre, 2002). https://www.globalsecurity.org/military/library/report/2002/summ-oruzgan-investigation.htm

Charlesworth, H., \& Chinkin, C. (2000). The boundaries of international law: A feminist analysis. University Press.

Chinkin, C., \& Kaldor, M. (2013). Gender and new wars. Journal of International Affairs, 67(1), 167-187. https://www.jstor.org/stable/24461677

Christie, N. (1986). The ideal victim. En E. A. Fattah (Ed.), From crime policy to victim policy: Reorienting the justice system (pp. 17-30). Palgrave Macmillan uK. https://doi.org/10.1007/978-1-349-08305-3_2

Cohn, C. (1993). Wars, wimps, and women: Talking gender and thinking war. En M. G. Convenio de Ginebra Relativo al Trato Debido a los Prisioneros de Guerra (Convenio III). (1949a).

Convenio de Ginebra Relativo a la Protección Debida a las Personas Civiles en Tiempo de Guerra (Convenio IV). (1949b).

Cooke \& A. Woollacott (Eds.). Gendering war talk (pp. 227-246). Princeton University Press.

Corte Penal Internacional. (2014). Documento de política sobre crímenes sexuales y por motivos de género.

Corte Penal Internacional. (1998). Estatuto de Roma.

Diakiese, H. Opening Remarks, Situation in the Democratic Republic of Congo, Prosecutor c. Lubanga, Trial Chamber I, Case No. ICC-01/04-01/0, 26 enero, 2009.

Dörmann, K. (2003). Elements of war crimes under the Rome Statute of the International Criminal Court: Sources and commentary. Cambridge University Press.

Doswald-Beck, L. (1987). The civilian in the crossfire. Journal of Peace Research, 24(3), 251-262. https://doi.org/10.1177/002234338702400305

Drumbl, M. A. (2012). Reimagining child soldiers in international law and policy. oup Oxford.

Enloe, C. (1998). All men are in the militias, all the women are victims: The politics of masculinity and feminity in nationalist wars. En L. A. Lorentzen \& J. E. Turpin (Eds.), The women and war reader (pp. 50-61). New York University Press. 
Fleck, D., \& Bothe, M. (Eds.). (2014). The handbook of international humanitarian law. Oxford University Press.

Gardam, J. (1997). An alien's encounter with the law of armed conflict. En N. Naffine \& R. J. Owens (Eds.), Sexing the subject of law (pp. 233-250) LBC Information Services.

Green, L. C. (2000). The contemporary law of armed conflict. Manchester University Press.

Grewal, K. K. (2015). International criminal law as a site for enhancing women's rights? Challenges, possibilities, strategies. Feminist Legal Studies, 23(2), 149-165. https://doi.org/10.1007/s10691-015-9286-4

Gustavsson, M., Oruut, J., \& Rubenson, B. (2017). Girl soldiers with Lord's Resistance Army in Uganda fighting for survival: Experiences of young women abducted by LRA. Children's Geographies, 15(6), 690-702. https:// doi.org/10.1080/14733285.2017.1300233

de Guzman, M. (2011). Crimes against humanity. En B. S. Brown (Ed.), Research handbook on international criminal law (pp. 62-83). Edward Elgar Publishing.

de Guzman, M. (2012). Crimes against humanity. En W. A. Schabas (Ed.), Routledge handbook of international criminal law (pp. 121-137). Routledge.

Heathcote, G. (2016). Laws, Ufos and UAvs: Feminist encounters with the law of armed conflict. En D. Stephens \& P. Babie (Eds.), Imagining Law: Essays in Conversation with Judith Gardam (pp. 153-170). University of Adelaide Press. https://www.jstor.org/stable/10.20851/j.ctt1sq5x0z.11

Heathcote, G., Jones, E., Labenski, S., \& Bertotti, S. (2021). The law of war and peace: A gender analysis, volume 1. Zed Books. http://ebookcentral.proquest.com/ lib/latrobe/detail.action?docID $=6419521$

Henckaerts, J.-M., \& Doswald-Beck, L. (2005). Customary international humanitarian law, volume 1. Cambridge University Press.

Hodgson, N. (2017). Gender justice or gendered justice? Female defendants in international criminal tribunals. Feminist Legal Studies, 25(3), 337-357. https://doi.org/10.1007/s10691-017-9359-7

Jaworski, E. (2003). "Military necessity" and "civilian immunity": Where is the balance? Chinese Journal of International Law, 2(1), 175-206. 
Jones, A. (2000). Gendercide and genocide. Journal of Genocide Research, 2(2), 185-211. https://doi.org/10.1080/713677599

Kinsella, H. M. (2006). Gendering grotius: Sex and sex difference in the laws of war. Political Theory, 34(2), 161-191. https://doi.org/10.1177/0090591705279530

Kinsella, H. M. (2011). The image before the weapon: A critical history of the distinction between combatant and civilian. Cornell University Press.

Levi, P. (1989). Los hundidos y los salvados (trad. P. G. Bedate). Muchnik Editores.

Lindsey, C. (2001). Women facing war. ICRC.

Mazurana, D. (2012). Women, girls, and non-state armed opposition groups. En C. Cohn \& C. H. Enloe (Eds.), Women and wars: Contested histories, uncertain futures (pp. 146-168). Wiley. http://ebookcentral.proquest.com/lib/latrobe/ detail.action?docID=1166791

Melzer, N. (2014). The principle of distinction between civilians and combatants. En A. Clapham \& P. Gaeta (Eds.), The Oxford handbook of international law in armed conflict. Oxford University Press.

Moser, C. O. N. (2001). Victims, perpetrators or actors? Gender, armed conflict and political violence. Zed Books.

Norman, R. (1995). Ethics, killing, and war. New York University Press.

Official records of the diplomatic conference on the reaffirmation and development of international humanitarian law applicable in armed conflicts 1974-1977.

Organización de las Naciones Unidas, Asamblea General. Conferencia Diplomática de Plenipotenciarios de las Naciones Unidas sobre el Establecimiento de una Corte Penal Internacional. 15 de junio a 17 de julio de 1998, Roma, Italia.

Organización de las Naciones Unidas. (2004). Estatuto de las Salas Extraordinarias de las Cortes de Camboya.

Organización de las Naciones Unidas, Comisión de Derechos Humanos. (27 abril, 2000). Resolution 2000/60, Abduction of children from northern Uganda, E/ CN.4/RES/2000/60.

Organización de las Naciones Unidas, Oficina del Alto Comisionado de Derechos Humanos. (1993). Estatuto del Tribunal Internacional Penal para Yugoslavia. https://www.ohchr.org/SP/ProfessionalInterest/Pages/InternationalTribunalForTheFormerYugoslavia.aspx 
Organización de las Naciones Unidas, Oficina del Alto Comisionado de Derechos Humanos. (1994). Estatuto del Tribunal Internacional Penal para Ruanda. https://www.ohchr.org/sp/ProfessionalInterest/Pages/StatuteInternationalCriminalTribunalForRwanda.aspx

Organización de las Naciones Unidas, Oficina del Alto Comisionado de Derechos Humanos. (2002). Estatuto del Tribunal Especial para Sierra Leona. https:// legal.un.org/avl/pdf/ha/scsl/scsl_s.pdf

Protocolo I Adicional a los Convenios de Ginebra de 1949 relativo a la protección de las víctimas de los conflictos armados internacionales. (1977a).

Protocolo II Adicional a los Convenios de Ginebra de 1949 relativo a la protección de las víctimas de los conflictos armados sin carácter internacional. (1977b).

Roberts, A. (2019). Foundational myths in the laws of war: The 1863 Lieber Code, and the 1864 Geneva Convention Lecture. Melbourne Journal of International Law, 20(1), 158-196.

Robinson, D. (1999). Defining 'crimes against humanity' at the Rome Conference. The American Journal of International Law, 93(1), 43-57. https://doi. org/10.2307/2997955

Rodenhäuser, T. (2018). Organizing rebellion: Non-state armed groups under international humanitarian law, human rights law, and international criminal law. Oxford University Press.

Rogers, A. P. V. (1996). Law on the battlefield. Manchester University Press.

Schabas, W. (2007). An introduction to the International Criminal Court. Cambridge University Press.

Shepherd, L. (2008). Gender, violence and security: Discourse as practice. Zed Books. http://ebookcentral.proquest.com/lib/latrobe/detail.action?docID=368675

Singer, P. W. (2015). Children at war. Knopf Doubleday Publishing Group.

Sivakumaran, S. (2010). Lost in translation: UN responses to sexual violence against men and boys in situations of armed conflict. International Review of the Red Cross, 92(877), 259-277. https://doi.org/10.1017/S1816383110000020

Slim, H. (2016). Civilians, distinction, and the compassionate view of war. En H. Willmot et al. (Eds.), Protection of civilians (pp. 11-28). Oxford University Press. https://doi.org/10.1093/acprof:oso/9780198729266.001.0001 
Triffterer, O., \& Ambos, K. (Eds.). (2016). Rome Statute of the International Criminal Court: A commentary. Beck/Hart.

Zarkov, D. (2001). The body of the other man: Sexual violence and the construction of masculinity, sexuality and ethnicity in Croatian media. En C. O. N. Moser (Ed.), Victims, perpetrators or actors? Gender, armed conflict and political violence (pp. 69-82). Zed Books.

\section{Jurisprudencia}

\section{ICC}

Prosecutor v. Bemba Gombo, Judgement (Trial Chamber III), Case No. ICC01/05-01/08, 21 March 2016.

Prosecutor v. Katanga, Judgement (Trial Chamber II), Case No ICC-01/04-01/07, 7 March 2014.

Prosecutor v. Kenyatta et al, Decision on the Confirmation of Charges (Pre-Trial Chamber II), Case No. ICC-01/09-02/11, 23 January 2012.

Prosecutor v. Lubanga, Judgement (Trail Chamber I), Case No, ICC-01/04-01/06, 14 March 2012.

Prosecutor v. Ntaganda, Judgement (Trial Chamber IV), Case No ICC-01/0402/06, 8 July 2019.

Prosecutor v. Ongwen, Judgement (Trail Chamber IX), Case No. ICC-02/04-01/15, 4 February 2021.

\section{ICTY}

Prosecutor v. Blaškić, Appeal Judgement (Appeals Chamber), Case No. IT-9514-A, 29 July 2004.

Prosecutor v. Češić, Judgement (Trial Chamber I), Case No. IT-95-10/1-S,11 March 2004.

Prosecutor v. Erdemović, Appeals Judgement (Appeals Chamber), Case No. IT-9622, 7 October 1997.

Prosecutor v. Mucić et al, Judgement (Trial Chamber), Case NoIT-96-21-T, 16 November 1998.

Prosecutor v. Simić et.al., Judgement (Trial Chamber II), Case NoIT-95-9-T, 2003. 
Prosecutor v. Stakić, Judgement (Trial Chamber II), Case No. IT-94-24, 31 July 2003.

\section{ICTR}

Prosecutor v. Kayishema and Ruzindana, Judgement (Trial Chamber II), Case No. ICTR-95-1-T, 21 May 1999.

Prosecutor v. Nahimana et al., Judgement (Trial Chamber I), Case No. ICTR-9952, 3 December 2003.

Prosecutor v. Bagosora et al., Judgement (Trial Chamber I), Case No. ICTR-9841-T, 18 December 2008.

Prosecutor v. Rutaganira, Judgement (Trial Chamber III), Case No. ICTR-95-1C, 14 March 2005.

\section{Salas Extraordinarias de las Cortes de Camboya}

Case 001, Prosecutors v. Kaing Guek Eav alias Duch, Judgement (Trial Chamber), Case No. 001/18-07-2007/ECCC/TC, 26 July 2010.

\section{Tribunal Especial para Sierra Leona}

Prosecutor v. Brima et al, Judgement (Trial Chamber II), Case No. SCSL-04-16-T, 20 June 2007.

Prosecutor v. Sessay et al. Judgement (Trial Chamber I), Case No. SCSL-04-15-T, 2 March 2009.

Prosecutor v. Taylor, Judgement (Trial Chamber II), Case No. SCSL-03-1-T, 26 April 2012.

\section{Tribunal Militar de Nuremberg}

Nuremberg Judgement. Military Tribunal v. Göring et al, 1 October 1946. 